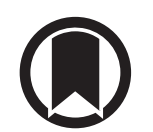

CrossMark

\title{
A harmonised European training syllabus for thoracic surgery: report from the ESTS/ERS task force group
}

\author{
Gilbert Massard ${ }^{1}$, Nathalie Tabin², Sharon Mitchell ${ }^{2}$, Hasan Batirel ${ }^{3}$, \\ Alessandro Brunelli ${ }^{4}$, Stefano Elia ${ }^{5}$, Anna Frick ${ }^{6}$, Martin Huertgen ${ }^{7}$, \\ Antoon Lerut ${ }^{6}$, Laureano Molins ${ }^{8}$, Kostas Papagiannopoulos ${ }^{4}$, \\ Dragan Subotic $9,10,11$, Paul van Schil ${ }^{12}$, Gonzalo Varela ${ }^{13}$ and \\ Dirk van Raemdonck ${ }^{6}$
}

Affiliations: ${ }^{1}$ Dept of Thoracic Surgery, Hôpitaux Universitaires de Strasbourg, Strasbourg, France. ${ }^{2}$ European Respiratory Society, Lausanne, Switzerland. ${ }^{3}$ Dept of Thoracic Surgery, Marmara University Hospital, Istanbul, Turkey. ${ }^{4}$ Dept of Thoracic Surgery, St James's University Hospital, Leeds, UK. ${ }^{5}$ Dept of Thoracic Surgery, University of Rome Tor Vergata, Rome, Italy. ${ }^{6}$ Dept of Thoracic Surgery, University Hospitals Leuven, Leuven, Belgium. ${ }^{7}$ Clinic of Thoracic Surgery, Catholic Clinic Koblenz-Montabaur, Koblenz, Germany. ${ }^{8}$ Dept of Thoracic Surgery, Hospital Clinic and Sagrat Cor, University of Barcelona, Barcelona, Spain. ${ }^{9}$ Dept of Thoracic Surgery, University Hospital Basel, Basel, Switzerland. ${ }^{10}$ Clinic for Thoracic Surgery, Clinical Center of Serbia, Belgrade, Serbia. ${ }^{11}$ School of Medicine, University of Belgrade, Belgrade, Serbia. ${ }^{12}$ Dept of Thoracic and Vascular Surgery, Antwerp University Hospital and Antwerp University, Antwerp, Belgium. ${ }^{13}$ School of Medicine, Salamanca University, Salamanca, Spain.

Correspondence: Nathalie Tabin, European Respiratory Society, 4 Avenue Ste-Luce, 1003, Lausanne, Switzerland. E-mail: nathalie.tabindersnet.org

@ERSpublications

A harmonised European training syllabus for thoracic surgery is now available http://ow.ly/xQMP30iZ50E

Cite this article as: Massard G, Tabin N, Mitchell S, et al. A harmonised European training syllabus for thoracic surgery: report from the ESTS/ERS task force group. Eur Respir J 2018; 51: 1800370 [https://doi. org/10.1183/13993003.00370-2018].

As has been reported for respiratory medicine, a high variance exists among European countries in the content and modes of delivery for specialty training in thoracic surgery. According to a survey by the Union Européenne des Médecins Spécialistes (UEMS; European Union of Medical Specialists) section of thoracic surgery conducted in 2013, disparities begin at the certifying body level: the specialist diploma is delivered by the ministry of health in half of the countries, and by various other authorities in the remaining countries [1]. Additionally, the designation of the specialty differs considerably: in 13 countries, thoracic surgery is practised as a monospecialty; in eight countries, it is combined with cardiac surgery; and in two countries (Belgium and Luxembourg), the designation does not exist.

Divergence also exists in length and content of training programmes. While the median duration is 6 years, the range extends from 5 years (e.g. in Spain and Italy) to 10 years (in Switzerland) [1]. Exposure to pure thoracic surgery during training ranges from 2 to 5 years [1]. Exposure to cardiac surgery is evidently mandatory in countries preparing for a cardiothoracic diploma. However, in those countries where thoracic surgery is a monospecialty, inclusion of exposure to cardiac surgery into the curriculum is not always mandatory. 
An additional conflicting question pertains to the number of operations to be performed as an operating surgeon during the training period. Since its inception, the European Board of Thoracic Surgery mandates 100 operations, which is slightly below the median number of 120 operations required in the UEMS member states (albeit a median based on a significantly large range, 35-560 operations). Indeed, there are at present nine countries that have yet to define a minimal requirement of surgical experience.

Lastly, the number of officially recognised training programmes is subject to high variability, ranging from one per 0.6 million to one per 6.1 million inhabitants (median of one per 1.6 million). The immediate consequence is that dissimilar training curricula and competence profiles add to language barriers and adversely interfere with mobility of healthcare professionals throughout Europe. Furthermore, uneven qualification of professionals may also lead to inequity of quality of care offered to patients.

The European Respiratory Society (ERS) made a pioneering step towards harmonisation of specialist training in Europe when launching the HERMES (Harmonised Education in Respiratory Medicine for European Specialists) initiative in 2006. Under the HERMES initiative, ERS established a strong curriculum design methodology, which has been used across ERS projects by task forces. Considering the disparities in training of pulmonary physicians, the first ERS task force defined a harmonised curriculum for training in adult respiratory medicine $[2,3]$, and a yearly examination in adult respiratory medicine has been conducted since 2008 [4]. Several satellite projects in subspecialties have followed, such as paediatric respiratory medicine [5], sleep medicine [6], critical care [7], infectious diseases [8] and thoracic oncology [9].

Given the disparity of training in thoracic surgery, but also because of an existing UEMS/European Board of Thoracic Surgery examination evolving without consensual definition of prerequisites, the need for a curriculum design task force was obvious. The European Society of Thoracic Surgeons (ESTS) were offered the opportunity to cooperate with ERS and to set up a task force group at the end of 2014, co-chaired by Dirk Van Raemdonck and Gilbert Massard. The partnership between ESTS and ERS has been largely effective. While ESTS has a clear vision on training issues in thoracic surgery, ERS masters the Delphi methodology, which has been successfully applied to eight curriculum design task forces prior to the present project. The latter begins with a problem statement, followed by the successive steps of defining a syllabus, describing the training curriculum, developing an examination, and accrediting training programmes.

The task force group has now published the recently acquired consensual European syllabus for thoracic surgery in the European Journal of Cardio-Thoracic Surgery [10]. The syllabus is presented in three parts. Part 1 contains the fundamentals, which a trainee should master at the beginning of their training; part 2 is dedicated to the knowledge of the diseases and disorders; and part 3 summarises operative skills. The task force elected to separate pure knowledge and operative skills for the sake of clarity, as the learning processes differ and, indeed, both are required to train a competent thoracic surgeon.

Some complexities stemmed from areas that are not practised in every unit, such as oesophageal surgery, paediatric thoracic surgery and lung transplantation. The latter modules were rated as "optional" by the subsequent Delphi rounds, while the core substance of the specialty is allocated to mandatory modules.

The target audience for this syllabus is primarily the European thoracic surgical trainee; however, the syllabus is also a guide for continuous professional development. Some modules may be useful to other specialty training programmes: for instance, modules concerning the oesophagus may be used by upper gastrointestinal specialists, and modules concerning paediatric thoracic surgery may be interesting for paediatric surgeons. Recent experience has demonstrated that curriculum design intended for the European continent may also find interested parties in North America [11, 12]!

Adequate training is crucial to prepare younger colleagues for safe, independent practice. There are numerous cases reported of missing training items that are exposed in the early years of autonomy [13, 14]. For this reason, we invited a Junior Member Representative (Anna Frick) into the ESTS committee for learning affairs, to take on an active role in the task force.

The present syllabus is a multifunctional tool. Chiefly, it serves for the ongoing curriculum design, which encompasses knowledge, psychomotor skills, professional attitudes, learning outcomes and modes of assessment. The task force is currently in the process of dissemination to national scientific and professional societies, with the goal of introducing a road map for the training programme to both learners and teachers. Obviously, the mandatory modules represent the prerequisite for the European Board of Thoracic Surgery examination.

In the future, online training programmes may be organised in accordance with the syllabus; such programmes are proving to be of interest for residents with intermediate learning progress [15]. 
Nonetheless, we should be aware that, despite any existing guidelines or regulations, there may remain differences in the content of training between programmes or between individuals in the same programme $[16,17]$. Moreover, and undoubtedly, the challenge of the future of any teacher or training programme is represented by the rapid advances in the innovation of medical treatments and incoming technology [18].

Conflict of interest: N. Tabin is an employee of the European Respiratory Society. S. Mitchell is an employee of the European Respiratory Society. H. Batirel reports receiving honoraria from Johnson and Johnson, outside the submitted work.

\section{References}

1 Depypere LP, Lerut AE. Thoracic surgical training in Europe: what has changed recently? Ann Transl Med 2016; 4: 89.

2 Loddenkemper R, Séverin T, Eiselé JL, et al. HERMES: a European Core Syllabus in Respiratory Medicine. Breathe 2006; 3: 59-69.

3 Loddenkemper R, Haslam PL, Séverin T, et al. European Curriculum Recommendations for Training in Adult Respiratory Medicine. Breathe 2008; 5: 80-93.

4 Loddenkemper R, Haslam PL. Multiple choice and the only answer: the HERMES examination. Breathe 2008; 4: $242-248$.

5 Gappa M, Noël JL, Séverin T, et al. Paediatric HERMES: a European Syllabus in Paediatric Respiratory Medicine. Breathe 2009; 5: 236-247.

6 De Backer W, Simonds A, Horn V, et al. Sleep HERMES: a European Core Syllabus in respiratory disorders during sleep. Breathe 2011; 8: 61-68.

7 Artigas A, Pelosi P, Dellweg D, et al. Respiratory critical care HERMES syllabus: defining competencies for respiratory doctors. Eur Respir J 2012; 39: 1294-1297.

8 Niculescu A, Noël JL, Aliberti S, et al. Introducing a new HERMES project on respiratory infections. Breathe 2016; 12: $5-7$.

9 Gamarra F, Noël JL, Brunelli A, et al. Thoracic oncology HERMES: European curriculum recommendations for training in thoracic oncology. Breathe 2016; 12: 249-255.

10 Massard G, Tabin N, Mitchell S, et al. A harmonized European training syllabus for thoracic surgery: report from the ESTS-ERS task force. Eur J Cardiothorac Surg 2018; in press [https://doi.org/10.1093/ejcts/ezy206].

11 Massard G, Antonoff MB, Noel JL, et al. Transatlantic editorial: thoracic surgeons need recognition of competence in thoracic oncology. J Thorac Cardiovasc Surg 2017; 154: 1387-1392.

12 Groth SS, Burt BM. Subspecialty certification in thoracic oncology: toward your next diploma. J Thorac Cardiovasc Surg 2017; 154: 1393-1394.

13 Chu D, Vaporciyan $\mathrm{AA}$, Iannettoni $\mathrm{MD}$, et al. Are there gaps in current thoracic surgery residency training programs? Ann Thorac Surg 2016; 101: 2350-2355.

14 Kraev A, Merritt-Genore H. Hello from the other side: what I wish I'd done differently in training. $J$ Thorac Cardiovasc Surg 2017; 153: 1434-1436.

15 Antonoff $\mathrm{MB}$, Verrier ED, Allen MS, et al. Impact of moodle-based online curriculum on thoracic surgery in-training examination scores. Ann Thorac Surg 2016; 102: 1381-1386.

16 Stephens EH, Walters DM, Eilers AL, et al. Variability in integrated cardiothoracic training program curriculum. Ann Thorac Surg 2017; 103: 1984-1991.

17 Stephens EH, Robich MP, Walters DM, et al. Gender and cardiothoracic surgery training: specialty interests, satisfaction, and career pathways. Ann Thorac Surg 2016; 102: 200-206.

18 Robich MP. The most important lessons I learned in training. J Thorac Cardiovasc Surg 2017; 154: 1015-1016. 